\title{
Review
}

\section{Reproductive disorders in hairdressers and cosmetologists: a meta-analytical approach}

\author{
Jean-Bernard Henrotin ${ }^{1}$, Cyndie Picot $^{2}$, Myriam Bouslama ${ }^{1}$, Dorothée Collot-Fertey ${ }^{3}$, \\ Anca RAdAUCEANU ${ }^{1}$, Marie-thérèse LABro ${ }^{4}$, Béatrice LARroque, Alain-Claude Roudot ${ }^{5}$, \\ Nessryne SATER ${ }^{2}$, Mostafa Ould ElHKim and Dominique LAFON ${ }^{1}$ \\ ${ }^{1}$ National Research and Safety Institute, France, ${ }^{2}$ National Agency for Medicines and Health Products Safety, France, \\ ${ }^{3}$ Objectif Santé Travail, France, ${ }^{4}$ National Institute of Health and Medical Research, France and ${ }^{5}$ University of Brest, \\ France
}

\begin{abstract}
Reproductive disorders in hairdressers and cosmetologists: a meta-analytical approach: Jean-Bernard HENROTIN, et al. National Research and Safety Institute, France-Objectives: The aim of this study was to perform a systematic review and to use a meta-analytical approach to assess quantitatively the risk of adverse pregnancy outcomes in hairdressers and cosmetologists. Methods: A systematic literature search up to 1 February 2012 was carried out using major bibliographic databases, grey literature, contacts with research teams working on the subject, review papers and reference lists of selected articles. Observational studies reporting measures of effects in relation with body care (hairdressers, cosmetologists, etc.) and reproductive disorders were included. Study quality was assessed by three reviewers. The estimated risk ratios (RR) from all studies reporting on identical outcomes were combined using an average of logarithm transformation of estimated RR weighted by their inverted variance. Statistical heterogeneity across studies was assessed using Cochran's $Q$ test. To explore the sources of heterogeneity, several sensitivity analyses and subgroup analyses were conducted based on study quality, country, study period, alcohol consumption, smoking habit, jobs and control populations. Results: Nineteen studies were selected and reviewed in-depth. The combined risk ratios (RRcs) of five reproductive outcomes were calculated and found to be significantly increased for four outcomes: time to pregnancy, which had an RRc of $1.11(95 \% \mathrm{Cl}: 1.03-1.19)$; premature birth, which had an RRc of 1.05 (95\% Cl: 0.99-1.11);
\end{abstract}

Received Mar 7, 2015; Accepted Jun 30, 2015

Published online in J-STAGE Aug 12, 2015

Correspondence to: J.-B. Henrotin, National Research and Safety Institute, Vandoeuvre-lès-Nancy, 54519, France (e-mail: jeanbernard.henrotin@inrs.fr)

Supplementary table: refer to J-STAGE: https://www.jstage.jst. go.jp/browse/joh small for gestational age, which had an RRc of 1.24 (95 $\mathrm{Cl} \%$ : 1.10-1.41); low birth weight, which had an RRc of 1.21 (95\% Cl: 1.06-1.39); and embryonic and fetal losses, which had an RRc of 1.19 (95\% Cl: 1.03-1.38). Conclusions: This work confirms a weak increase in risk of some reproductive disorders in female hairdressers/cosmetologists. However, the evidence level is rather weak, and a causal association between job and reproductive outcomes cannot be asserted.

(J Occup Health 2015; 57: 485-496)

Key words: Cosmetologists, Hairdressers, Metaanalysis, Reproduction epidemiology

Hairdressers and cosmetologists constitute a major occupational group of predominantly female workers, many of whom are of childbearing age. Hairdressers use continuously a wide range of products, such as shampoos, hair dyes, perm solutions, detergents, perfumes, and hair sprays ${ }^{1)}$. Cosmetologists perform manicures, pedicures, facials, and other beauty treatments. In some countries (e.g., USA), cosmetologists can also be hairdressers. In these two jobs, all the used products can contain in large part the same chemical substances. For certain chemical substances, reproductive toxicity has been reported in animal studies, but with insufficient evidence in humans (organic solvents, aromatic amines, formaldehyde, phthalates, etc. ${ }^{2-5)}$. Both dermal absorption and inhalation are relevant exposure routes for hairdressers and cosmetologists ${ }^{6,7)}$. It is also noteworthy that these occupations involve physical exertion, long periods of standing and walking in the workplace, awkward postures, and psychosocial factors that can potentially interfere with reproduction ${ }^{8-10)}$. Consequently, the presence of incriminated substances in cosmetic products and working conditions can generate concern regarding the 
reproductive risks in these occupational groups ${ }^{1,11,12)}$ Actually, the risk of reproductive disorders in hairdressers has been examined in several epidemiological studies. However, their small sample sizes and the resulting lack of statistical power explain why the results of these studies have been considered inconsistent and why significant associations have rarely been found. Moreover, the associations examined in previous reviews between the occupations of hairdresser and/or cosmetologist and pregnancy outcomes have been qualitative rather than quantitative $\mathrm{e}^{1,11,12)}$.

The main aim of this work was to perform a systematic review and to use a meta-analytical approach to assess quantitatively the risk of adverse pregnancy outcomes in hairdressers and cosmetologists, to establish the overall strengths and consistency of these associations and to explore sources of heterogeneity. To our knowledge, no meta-analysis has yet been carried out on this topic.

\section{Methods}

Search strategy

A systematic literature search was carried out using MEDLINE and ScienceDirect from January 1966 up to February 2012 (Fig. 1). The following terms were searched: hairdresser, cosmetologist, beautician, mani- curist, nail salon, barbering, hair stylist, hairdressing profession, hairdressing occupation, professional hair care, beauty culture, maternal occupation, and paternal occupation combined with: reproduction, pregnancy, adverse reproduction effects, reproductive disorders, reproductive outcomes, and pregnancy outcomes. The outcome terms were: fertility, infertility, subfertility, menstrual disorders, menstruation disturbances, primary ovarian insufficiency, preterm birth, stillbirth, perinatal death, spontaneous abortion, low birth weight/LBW, small for gestational age/SGA, fetal growth retardation, fetal development, time to pregnancy/TTP, malformations, congenital malformation, congenital abnormalities, genital diseases, spermatogenesis, testis abnormalities, testis, and gametogenesis. The reference lists of the selected articles and previously published systematic reviews were examined to find additional relevant studies. The Cochrane Library database was also consulted. A search of grey literature was also performed, and several research teams working in the field of reproduction were contacted and asked about unpublished studies.

\section{Study selection}

Studies were included in this review if they met

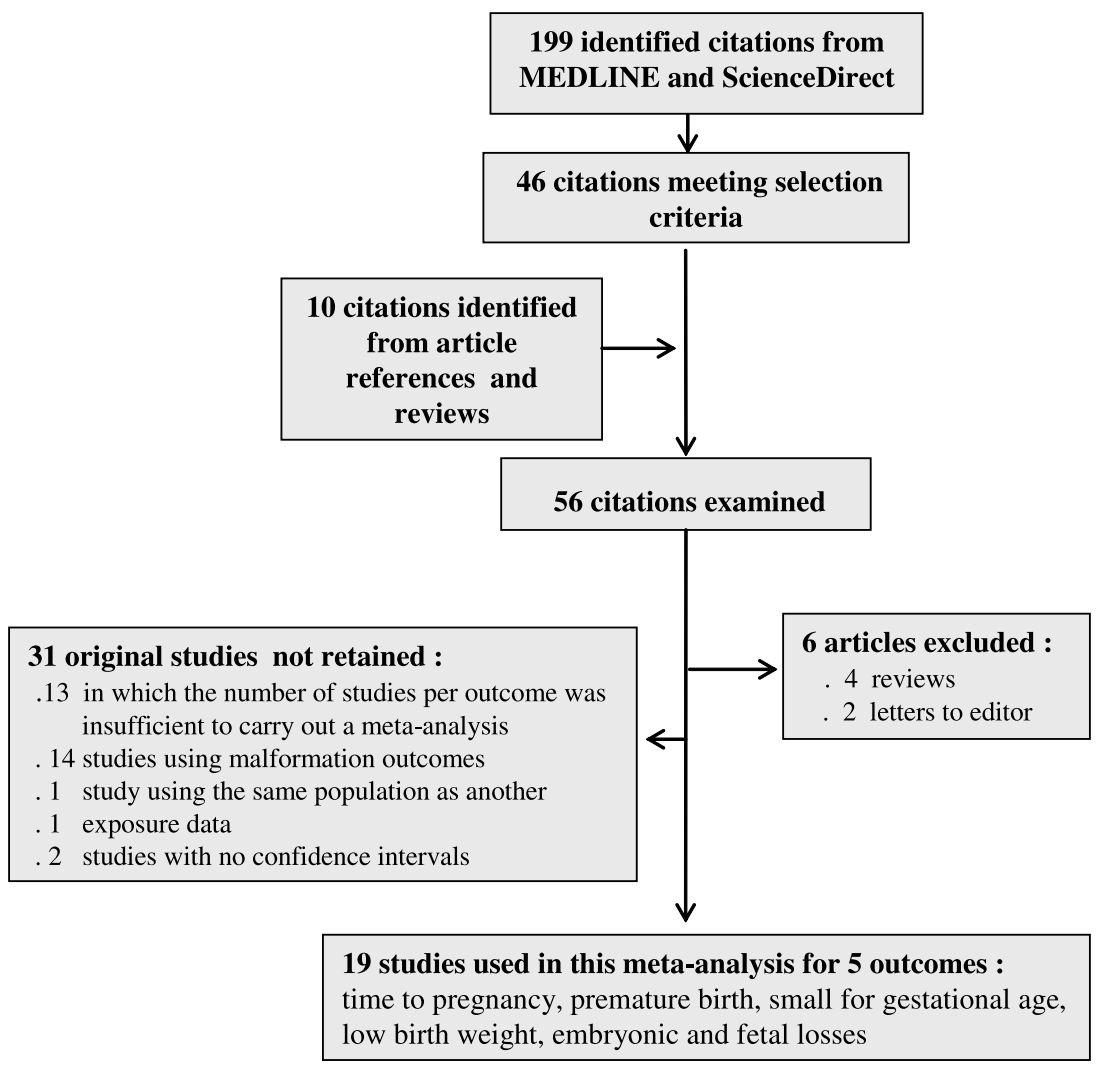

Fig. 1. Flow chart for selection of studies. 
all the following criteria: i. original English-language articles, ii. epidemiological studies of any design (cross-sectional, cohort, case-control, or register-based studies), iii. studies including occupational exposure to chemical products in body care (hairdressers, cosmetologists, beauticians, manicurists, barbers), iv. presence of at least one of the adverse reproductive outcomes as mentioned above, and v. provision of epidemiologic measures of effects (relative risk, odds ratio, rate ratio, hazard ratio, and so on) and their confidence intervals (CIs) or at least available data to calculate risk estimators (observed and expected cases).

\section{Data extraction and quality assessment}

The following main data were extracted from selected studies (some of this information is summarized in Table 1; see Supplementary Table A online): author(s); year of publication, country of origin, study period, study design, outcome(s), study population size, number of cases by group (exposed and nonexposed); types of control populations, confounding factors, and measures of association and CIs. The quality of observational studies was assessed independently by 5 reviewers (C-FD, AR, LMT, LR, RAC), and the studies were classified as good, acceptable, or unacceptable based on the recommendations of the "Meta-analysis Of Observational Studies in Epidemiology" guidelines ${ }^{13)}$. Discrepancies in classification were discussed, harmonized, and validated by all the reviewers. The quality of a study was considered good if it met three criteria: the relevant confounders were taken into account, the reported data were accurate and detailed, and the risk of bias was low. The sensitivity analysis consisted of comparing the results obtained by considering all the studies or excluding those with an unacceptable quality.

\section{Statistical analyses}

The estimated risk ratios (RRs) from all studies reporting identical end points were pooled, and combined risk ratios (RRcs) calculated using STATA software version 12.1 (StataCorp, College Station, TX, USA). The logarithm of the RRc was estimated as an average of the logarithmic transformation of the estimated RR values observed in each study, weighted by their inverted variance and presented with a 95\% CI. We preferentially pooled adjusted RR estimates from multivariable analysis using the most complex model when such estimates were available, but we included the unadjusted estimates when adjusted RR estimates were not available. Distributions of the estimated RRs from different studies and their 95\% CIs were examined graphically on forest plots ${ }^{14)}$. Statistical heterogeneity across studies was assessed using Cochran's
Q test: when $p<0.10$, the estimated risks were pooled using a random-effects models; when $p>0.10$, the fixed effect model was used ${ }^{14)}$. Potential publication bias was examined by constructing a funnel plot in which the standard error was plotted against the log RR and quantified by Egger's test ${ }^{15}$. The nonparametric "trim and fill" method of Duval and Tweedie was also used to measure the potential impact of publication bias in this meta-analysis ${ }^{14)}$. The influence of omission of each study was examined with respect to estimated effect measures in the meta-analysis ${ }^{14)}$. A cumulative meta-analysis according to the precision of the studies was also performed to examine the impact of study sizes on the estimation of $\mathrm{RRc}^{14)}$. To explore the sources of heterogeneity, we conducted several sensitivity and subgroup analyses based on study quality, study country (Europe versus North America), study period (before 1990 or after 990), adjustment for alcohol consumption, adjustment for smoking habit, target population (hairdressers or cosmetologists), and control population (salesclerks, working population, or general population).

\section{Results}

In all, 19 studies were extracted from the literature, making it possible to examine five outcomes: time to pregnancy (unprotected intercourses over a period of more than 12 months without a pregnancy), preterm birth (PB), small for gestational age (SGA), low birth weight (LBW), and embryonic and fetal losses. Figure 1 shows details of the study selection. The malformation outcomes were not retained because of the very wide diversity in the malformations studied; consequently, it was not possible to present all the results for malformation outcomes (Fig. 1; Supplementary Table A online). For other outcomes, the number of studies was insufficient to carry out a meta-analysis. The main characteristics of the 19 studies selected are summarized in Table 1.

\section{Time to pregnancy (TTP)}

One cohort study ${ }^{16)}$, three cross-sectional studies $^{17-19)}$, and two studies based on registers ${ }^{20,21)}$ were extracted from literature data (Table 1). Of these studies, only one was carried out on cosmetologists ${ }^{19)}$. Seven estimated RRs were retained to calculate RRcs (among which two estimates were from one study ${ }^{16)}$ ). Six estimated RRs were increased, but only two were statistically significant (Fig. 2) ${ }^{17,20)}$. A nonsignificant heterogeneity test $(p=0.13)$ suggested a homogeneous distribution of effect measures. Using a fixed effect model, the RRc increased significantly to 1.11 (95\% CI: 1.03-1.19). Additionally, there was no evidence of dose-response relationship with the number of technical tasks per week in two studies ${ }^{19,20)}$. Sensitivity 


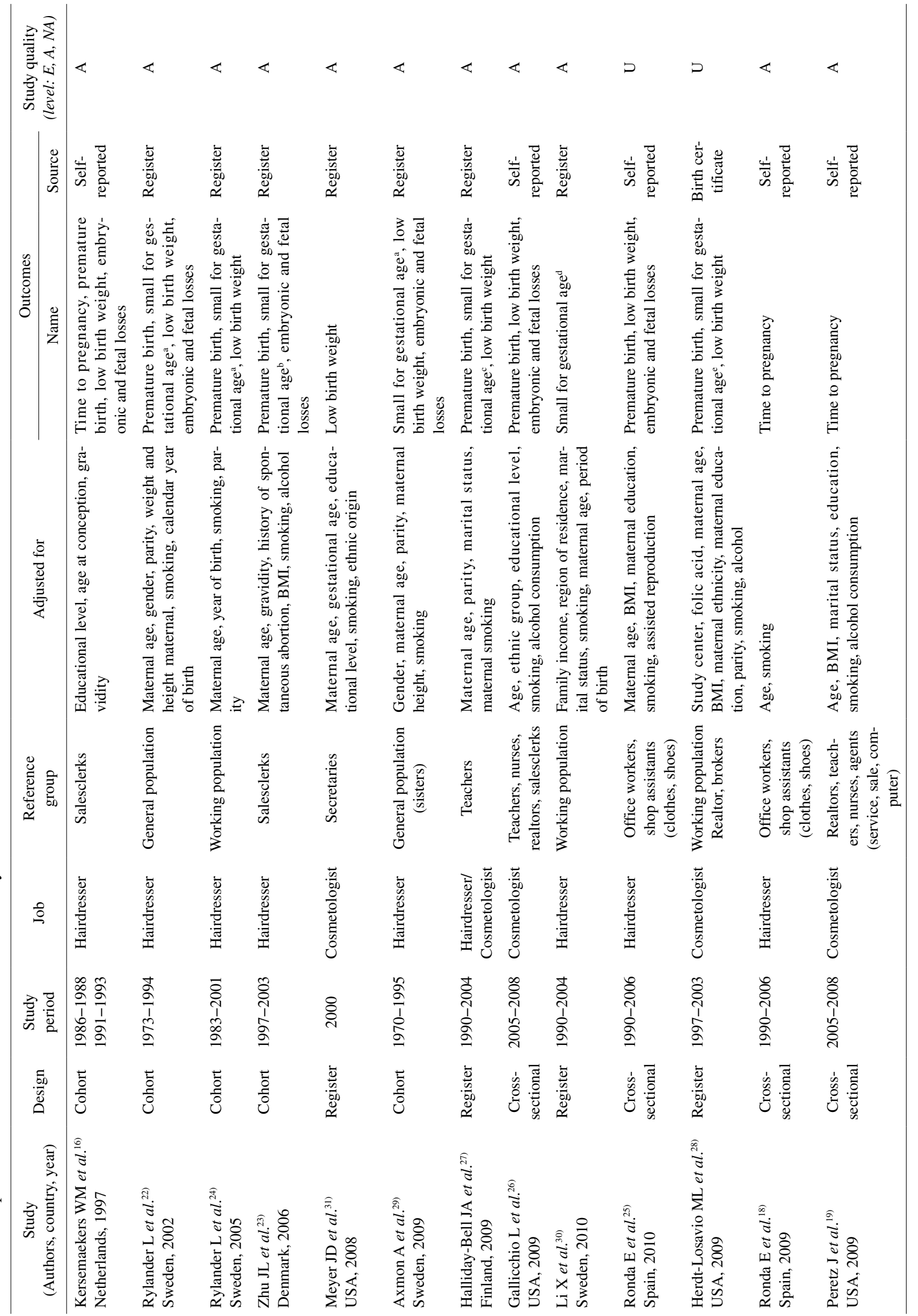


analyses (Table 2) showed an impact of adjustment for alcohol consumption but not for the other factors: $\mathrm{RR}_{\text {ajusted alcohol }}=1.09(95 \% \mathrm{CI}: 0.99-1.18)$ versus $\mathrm{RR}_{\text {no }}$ adjusted alcohol $=1.21(95 \% \mathrm{CI}: 1.02-1.44)$. In the reference groups, RRc was also higher for the salesclerk group than for the working population group: $\mathrm{RR}_{\text {salesclerk }}=1.19(95 \% \mathrm{CI}: 0.99-1.41)$ versus $\mathrm{RR}_{\mathrm{no}}$ salesclerk $=1.09$ (95\% CI: 1.004-1.18). Using the trimand-fill method, the imputed RRc was 1.09 (95\% CI: 1.01-1.17), which is similar to our estimated RRc, suggesting an absence of publication bias. The cumulative meta-analysis indicated that statistical significance at $p<0.05$ was achieved marginally in 2006 (data not shown). By examining the influence of the omission of each study on the RRc in the meta-analysis, no outlier study was detected (data not shown).

\section{Premature birth ( $<37$ weeks of gestation)}

The link with PB was analyzed in eight studies (four cohort studies ${ }^{16,22-24)}$, two cross-sectional studies ${ }^{25,26)}$, and two studies based on registers ${ }^{27,28)}$ ) (Table 1). Three studies were carried out on cosmetologists ${ }^{26-28)}$, and five other studies were carried out on hairdressers $^{6,22-25)}$. Eleven measures of association were extracted from eight studies, and ten were included in the meta-analysis. Only one study showed a significant increase in PB in hairdressers compared with teachers as referent group ${ }^{27}$. For the other studies, no significant results were reported ${ }^{16,22-26,28}$. Using a fixed effect model (heterogeneity test, $p=0.21$ ), RRc was not significantly increased $(\mathrm{RRc}=1.05$ (95\% CI: 0.99-1.11)). No dose-response relationship with the weekly number of technical tasks was observed in the single study where this question was examined ${ }^{22}$. In sensitivity analyses, we noted a decreased RR when adjusted for alcohol consumption: $\mathrm{RR}_{\text {ajusted alcohol }}=0.94$ (95\% CI: 0.82-1.08). All these studies were carried out in Europe. Studies on hairdressers reported a significantly increased risk $\left(\mathrm{RR}_{\text {hairdressers }}=1.09(95 \% \mathrm{CI}\right.$ : 1.02-1.17)), but this result was not found for cosmetologists $\left(\mathrm{RR}_{\text {cosmetologists }}=0.93\right.$ (95\% CI: $\left.0.82-1.04\right)$ ). When salesclerks were the reference group, RRc was lower than for the other control groups ( $\mathrm{RRc}=0.98$ (95\% CI: 0.76-1.27)). The other sensitivity analyses (cumulative meta-analysis, trim-and-fill method, outlier study research) did not change the results.

\section{Small for gestational age}

Eight estimates from seven studies (six cohort studies and one cross-sectional study, Table 1) were retained for this outcome. Two estimates were extracted for cosmetologists, and six estimates were extracted for hairdressers. The definitions of SGA were different in the included studies. A summary of the definitions for each study is shown below Table 


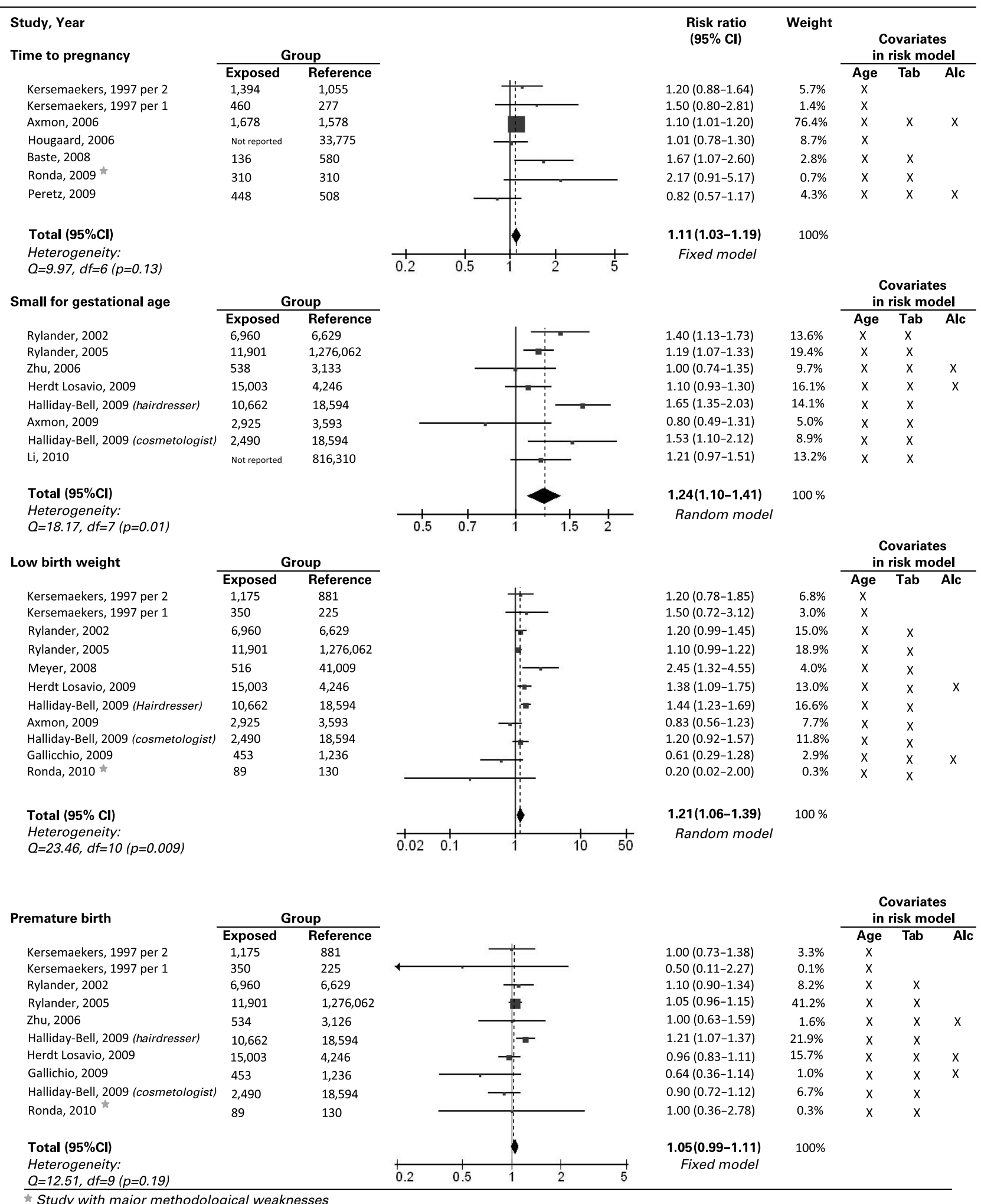

* Study with major methodological weaknesses

Fig. 2. Forest plot (time to pregnancy, small for gestational age, low birth weight, premature birth). 


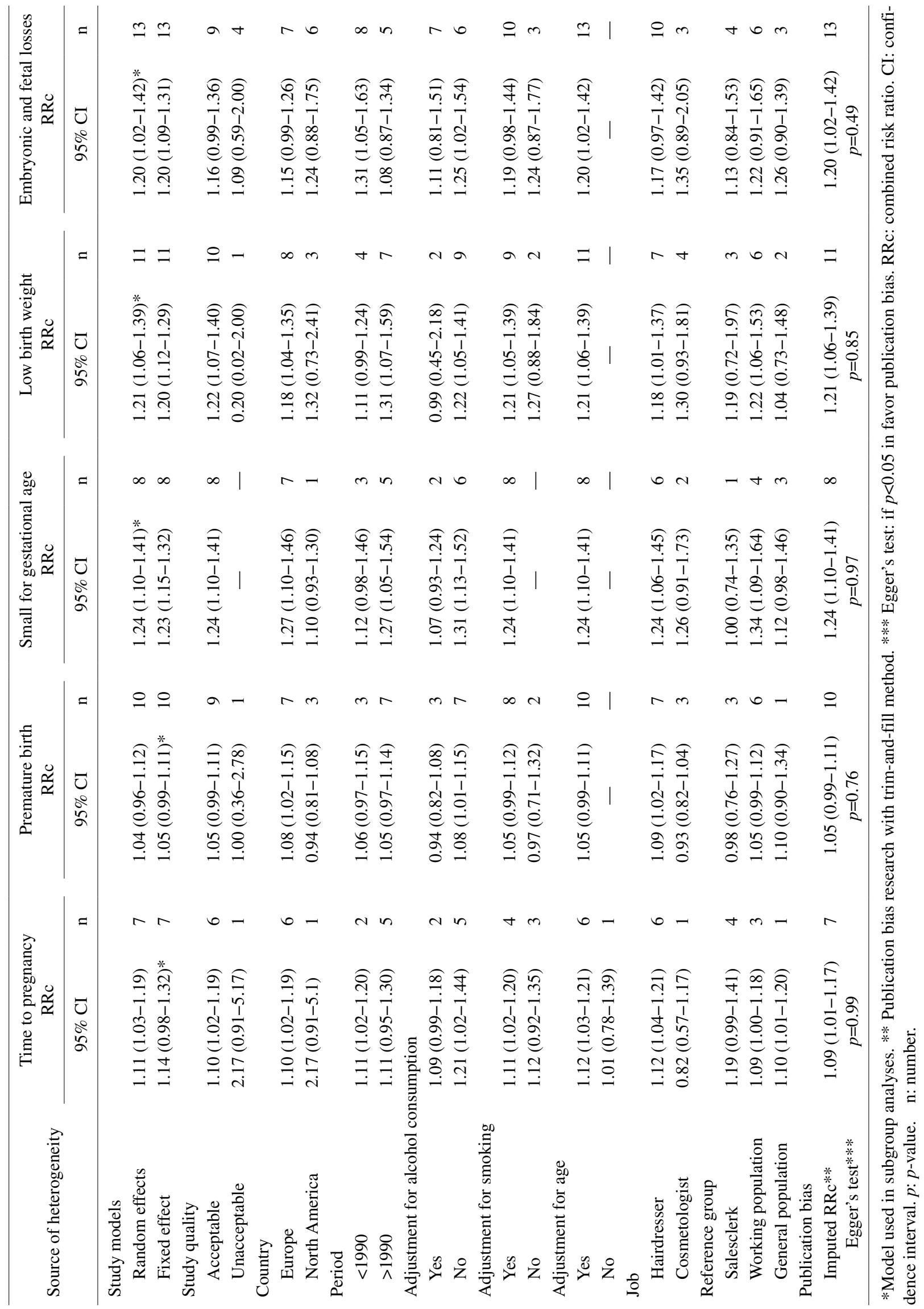




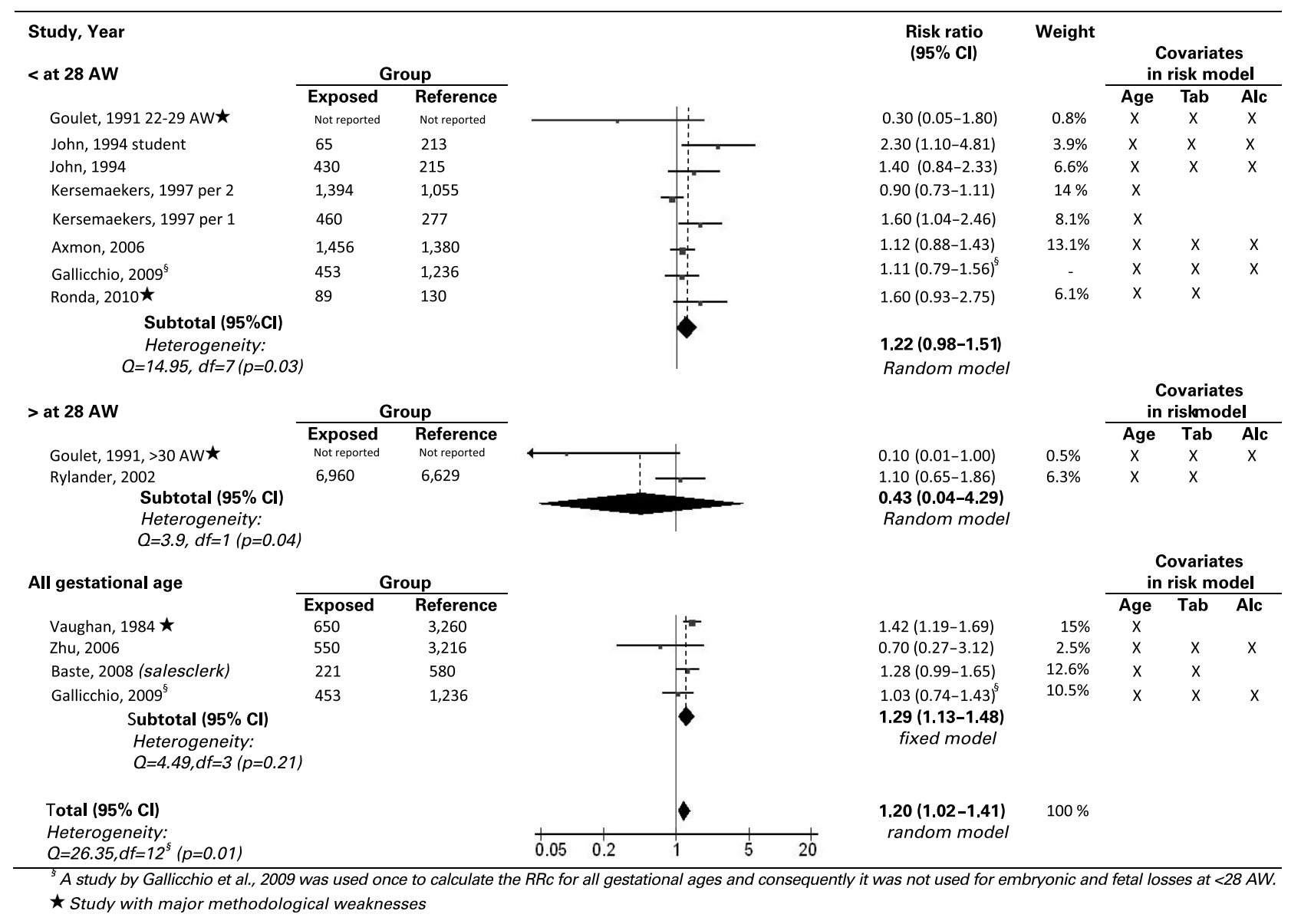

Fig. 3. Forest plot (embryonic and fetal losses).

1. Increased risk was observed in four studies: in hairdressers compared to the general population ${ }^{22,24)}$ and teachers ${ }^{27)}$; and in cosmetologists compared to teachers ${ }^{27)}$. The four other measures of association showed no significant link ${ }^{23,28-30)}$. Using a random effect model (heterogeneity test, $p=0.01$ ), the RRc in hairdressers and cosmetologists increased slightly but significantly (RRc=1.24 (95\% CI: 1.10-1.41)). In one study only, frequent permanent waving and spraying tended to be associated (though not significantly) with an increased risk of having an infant with $\mathrm{SGA}^{22)}$. In the sensitivity analyses (date, job title, control group), the pattern of strengths of association was not modified except for alcohol consumption: $\mathrm{RR}_{\text {ajusted alcohol }}$ $=1.07$ (95\% CI: 0.93-1.24) for two studies versus $\mathrm{RR}_{\text {no adjusted alcohol }}=1.31(95 \% \mathrm{CI}: 1.13-1.52)$ for six studies. The other sensitivity analyses (the trim-andfill method, outlier study research) did not change the results. The cumulative meta-analysis indicated that the statistical significance level had remained unchanged since 2002, the date of the first study (data not shown). Globally, the results seem robust to sensitivity analyses.
Low birth weight $(<2,500 \mathrm{~g})$

Nine studies examined reproductive disorders in relation with low birth weight, and eleven estimates were integrated in this meta-analysis. These estimates were calculated in two cross-sectional studies ${ }^{25,26)}$, four cohort studies ${ }^{16,22,24,29)}$ and three registers stud$\operatorname{ies}^{27,28,31)}$. Of these estimates, four were related to cosmetologists, and seven were related to hairdressers. Eight studies reported an increased risk of having an infant with LBW, and this increase was significant in three studies ${ }^{27,28,31)}$. Using a random model (heterogeneity test, $p=0.009$ ), the RRc increased significantly ( $R R c=1.21$ (95\% CI: 1.06-1.39)). This result was also not altered by removing a study of lower quality $^{25)}$. The robustness of this finding was observed in several subgroup analyses (country, period, job, reference group) and the other sensitivity analyses (the trim-and-fill method, outlier study research), except for alcohol consumption: $\mathrm{RR}_{\text {ajusted alcohol }}=0.99$ (95\% CI: 0.45-2.18) for only two studies versus $R_{\text {no adjusted alco- }}$ ${ }_{\text {hol }}=1.22$ (95\% CI: $\left.1.05-1.41\right)$ for nine studies. The cumulative meta-analysis indicated that statistical significance was observed in 2002 (data not shown). 
In the single study examining the question ${ }^{22}$, no doseresponse relationship between LBW and the number of technical tasks per week was found.

\section{Embryonic and fetal losses}

For this outcome, fourteen estimates from ten studies (three cohorts ${ }^{16,22,23)}$, two case-control stud$\operatorname{ies}^{32,33)}$, four cross-sectional studies ${ }^{17,25,26,34)}$, and one register study ${ }^{29}$ ) ) were integrated in the metaanalysis. Of them, two studies were carried out on cosmetologists $^{26,33)}$ and eight studies were carried out on hairdressers. In Fig. 3, the studies are presented according to three subgroups: embryonic or fetal loss ( $<28$ amenorrhea weeks (AW); $\geq 28 \mathrm{AW}$ ); regardless of gestational age) and all the studies. For all the studies, the RRc in a random model (heterogeneity test, $p=0.01$ ) was equal to 1.20 (95\% CI: $1.02-$ 1.41). Excluding the $\geq 28$ AW subgroup (only two studies $^{22,32)}$ one of which was of poor quality $\left.{ }^{32}\right)$, the RRcs of the subgroups were rather similar (Fig. 3). For the period of up to $24 \mathrm{AW}$ (data not shown), the strength of association was stronger but not significant $\left(\mathrm{RRc}=1.30\right.$ (95\% CI: 0.99-1.71)). One study ${ }^{33)}$ out of four ${ }^{20,23,25)}$ reported a dose-response relationship between spontaneous abortion and the number of weekly technical tasks. The results were stable in sensitivity analyses except for two situations (Table 2). As with all the other outcomes, adjustment for alcohol consumption led to a decrease in the strength of association (25\% versus 11\%; Table 2). Also, the RRc was lower after 1990, with the RRc for after 1990 being 1.08 (95\% IC: $0.87-1.34$ ) and that before 1990 being 1.31 (95\% IC: 1.05-1.63). The cumulative meta-analysis indicated that statistical significance was achieved in 2009 (data not shown). The other sensitivity analyses (trim-and-fill method, outlier study research) did not change the results.

\section{Discussion}

In this meta-analysis, a significant relationship (RRcs of 1.10 to 1.40 ) between the job of being a hairdressers/cosmetologists and the risk increase of reproductive disorders (TTP, fetal loss, LWB, SGA) was observed. No increased risk of PB was reported. These results were observed in several studies and in different countries, regardless of the reference groups retained, and they were similar regardless of the sensitivity of the analyses.

At least three types of occupational risk could explain these results in hairdressers/cosmetologists: physical risks ${ }^{8,9,35)}$, mental demands ${ }^{10)}$, and exposure to chemical products. As reported previously, long periods of standing, long working hours, manual handling of loads, and awkward postures are often associated with reproductive outcomes ${ }^{8,9,35)}$. Moreover,
Niedhammer et al. (2009) showed an increased risk of the occurrence of LWB and PB related to the combination of several occupational factors ${ }^{35)}$. Do arguments exist in favor of an impact of chemical agents $^{12)}$ ? In general, it is reported that for a given substance, exposure levels are low (ethanol, isopropanol, acetone, toluene, acetates, etc. $)^{1,36-38)}$, and if an impact exists on reproductive outcomes, it is expected to be rather limited. This hypothesis may be valid based on the results of the epidemiological studies examined in this review. On the one hand, overall, the range of values of RRc is rather weak, between 1.10 to 1.40 . On the other hand, this "global" risk of abnormal pregnancy is related to combined exposure to chemical, physical, and psychosocial risks and not only to chemical risk. However, the implication of chemical exposures in the occurrence of reproductive disorders in hairdressers cannot be ruled out. Indeed, several studies have compared hairdressers with salesclerks ${ }^{16-18,21,23,25)}$. This referent occupational group presents similar educational levels, socioeconomic statuses, levels of stress, and physical workload (standing, walking, physical exertion) but without exposures to chemicals used in hairdresser/cosmetologist salons. Compared with this referent group, hairdressers showed an increased risk of pregnancy disorders in several studies ${ }^{16-18,25)}$. Also, the effects of low doses and complex mixtures during fetal development could be explained by the possibility of endocrine disruptor mechanisms of cosmetic products ${ }^{39}, 40$ ). There is growing interest in possible health effects after exposure to endocrine disruptors ${ }^{41)}$. For instance, cosmetic product users can be exposed to substances that are suspected to be endocrine disrupters such as phthalate esters, ultraviolet filters, polycyclic musks, parabens and/or triclosan ${ }^{39,40,42)}$. In a Canadian study, 112 of 252 products tested were found to contain at least one phthalate at a detectable level ${ }^{43)}$.

The variations of the concentrations of chemical exposures were described in several studies ${ }^{37,38,44)}$. In general, chemical product concentrations vary according to the use of the specific products, the number and type of products that were opened during the measurements, the number of treatments performed, and workplace ventilation ${ }^{37,44)}$. These levels of substances could be significantly decreased in the work environment by using appropriate practices such as good ventilation, storage of beauty products in a separate room, or resealing product packages after use $^{37)}$. In order to reduce exposure to substances during technical tasks, it is recommended that users to wear gloves and use a ventilated enclosure. There is a need to provide information and training for employees on the possible toxic effects of chemicals as well as education on proper handling. For the ingredients 
of cosmetic products, however, it is often difficult for users to remains aware of changes in products (change in composition: substances, concentration, purity, etc.) when the commercial name remains the same or when information on the packaging, such as information about the hazards (safety data sheets) is newly added. Concerning physical exposure, it is recommended that users avoid long working hours, standing for prolonged periods of time, and handling heavy loads during pregnancy ${ }^{45}$.

To our knowledge, our work is the first to study the relation between the occupation of hairdresser/ cosmetologist and reproductive outcomes according to a meta-analytical approach. Our meta-analysis remedies the lack of power found in studies using small numbers of workers and including misclassifications of exposure. However, the different observational studies, such as those reviewed in this work, do not provide definitive proof of a causal association between work in hairdressing and beauty salons and certain reproductive outcomes. The level of evidence is rather weak for the following reasons:

First, in most studies there is no clear and detailed information regarding exposure (intensity, duration, frequency) and/or use of protective equipment (such as wearing of gloves or use of local exhaust ventilation). The nature of the chemical substances used in the workplace may be different from one study to another and depend on the period during which the study was conducted. Second, concerning the exposure to chemical products, few studies have examined and reported $^{20,22,33,46)}$ dose-response relationships between the exposure and reproductive outcomes observed ${ }^{20}$, 33). Third, several published studies pointed out that alcohol consumption, even when moderate, may also be associated with the same adverse birth outcomes as the ones they reported ${ }^{47}$. In this work, we observed substantial changes of RRc between groups with and without adjustment for alcohol consumption in several sensitivity analyses (Table 2). In the absence of this adjustment, overestimation of risk cannot be ruled out, and this point should be clarified by additional studies to distinguish between the risk due to cosmetic product exposure and/or that due to the alcohol consumption. Four, some relevant information on potential confounders was not available, such as information on the use of medication, paternal exposure, and dietary habits. For instance, a substantial exposure to reproductive substances would exist via foods. Fierens et al. (2012) hypothesized that food is the principle exposure pathway for phthalates ${ }^{48)}$. Some of phthalates are now known to affect human reproductive systems (fertility, hypospadias, cryptorchidism) $^{49}$.

\section{Conclusion}

This work confirms a weak increase in risk of some reproductive disorders in female hairdressers/ cosmetologists. Based on our data, the evidence level is rather weak, and a causal association between job and reproductive outcomes cannot be asserted. Also, our results have several implications. They should, however, be considered as an alert and a reason to ensure that individual and collective prevention measures are effectively employed in hairdressing and beauty salons, especially in the case of pregnant workers. Other epidemiological studies are needed to confirm the causal association. It is suggested that "alcohol consumption" should be integrated as confounding factor in future studies. Also, standardized information on medicine, food, dietary habits, and home exposure should be collected. In addition, the expected low RRs and the lack of power reported in these studies suggest the need for inclusion of a sample with larger number of workers. Furthermore, improved collection of exposure data regarding chemical exposure is needed. Only few studies took into account the dose-response relationships, and they unfortunately provided no information on the chemical products used in the workplace and during the pregnancy period. This lack of information prevents calculation of the risks attributable to reproductive disorders related to the cosmetic products used by this occupational group. Also, the current data do not allow to know the respective contributions of physical risks, mental demands and other chemical exposures in the increased risks observed in hairdressers and/or cosmetologists.

\section{References}

1) Kersemaekers WM, Roeleveld N, Zielhuis GA. Reproductive disorders due to chemical exposure among hairdressers. Scand J Work Environ Health 1995; 21: 325-34.

2) van Muiswinkel WJ, Kromhout H, Onos $T$, Kersemaekers W. Monitoring and modelling of exposure to ethanol in hairdressing salons. Ann Occup Hyg 1997; 41: 235-47.

3) Marks TA, Gupta BN, Ledoux TA, Staples RE. Teratogenic evaluation of 2-nitro-p-phenylenediamine, 4-nitro-o-phenylenediamine, and 2,5-toluenediamine sulfate in the mouse. Teratology 1981; 24: 253-65.

4) Lottrup G, Andersson AM, Leffers H, et al. Possible impact of phthalates on infant reproductive health. Int J Androl 2006; 29: 172-80.

5) Foster PM, Mylchreest E, Gaido KW, Sar M. Effects of phthalate esters on the developing reproductive tract of male rats. Hum Reprod Update 2001; 7: 231-5.

6) Lind ML, Boman A, Sollenberg J, Johnsson S, 
Hagelthorn G, Meding B. Occupational dermal exposure to permanent hair dyes among hairdressers. Ann Occup Hyg 2005; 49: 473-80.

7) Ronda E, Hollund BE, Moen BE. Airborne exposure to chemical substances in hairdresser salons. Environ Monit Assess 2009; 153: 83-93.

8) Bonzini M, Coggon D, Palmer KT. Risk of prematurity, low birthweight and pre-eclampsia in relation to working hours and physical activities: a systematic review. Occup Environ Med 2007; 64: 228-43.

9) Mozurkewich EL, Luke B, Avni M, Wolf FM. Working conditions and adverse pregnancy outcome: a meta-analysis. Obstet Gynecol 2000; 95: 623-35.

10) Dole N, Savitz DA, Hertz-Picciotto I, Siega-Riz AM, McMahon MJ, Buekens P. Maternal stress and preterm birth. Am J Epidemiol 2003; 157: 14-24.

11) Peters C, Harling M, Dulon M, Schablon A, Torres Costa J, Nienhaus A. Fertility disorders and pregnancy complications in hairdressers - a systematic review. J Occup Med Toxicol 2010; 5: 24.

12) Chua-Gocheco A, Bozzo P, Einarson A. Safety of hair products during pregnancy: personal use and occupational exposure. Can Fam Physician 2008; 54: $1386-8$.

13) Stroup DF, Berlin JA, Morton SC, et al. Metaanalysis of observational studies in epidemiology: a proposal for reporting. Meta-analysis of Observational Studies in Epidemiology (MOOSE) group. JAMA 2000; 283: 2008-12.

14) Sterne JAC. Meta-analysis in Stata: an updated collection from the Stata journal. 2009. College Station, TX: Stata Press.

15) Egger M, Davey Smith G, Schneider M, Minder C. Bias in meta-analysis detected by a simple, graphical test. BMJ 1997; 315: 629-34.

16) Kersemaekers WM, Roeleveld N, Zielhuis GA. Reproductive disorders among hairdressers. Epidemiology 1997; 8: 396-401.

17) Baste V, Moen BE, Riise T, Hollund BE, Øyen N. Infertility and spontaneous abortion among female hairdressers: the Hordaland Health Study. J Occup Environ Med 2008; 50: 1371-7.

18) Ronda E, Garcia AM, Sánchez-Paya J, Moen BE. Menstrual disorders and subfertility in Spanish hairdressers. Eur J Obstet Gynecol Reprod Biol 2009; 147: 61-4.

19) Peretz J, Gallicchio L, Miller S, Greene T, Zacur H, Flaws JA. Infertility among cosmetologists. Reprod Toxicol 2009; 28: 359-64.

20) Axmon A, Rylander L, Lillienberg L, Albin M, Hagmar L. Fertility among female hairdressers. Scand J Work Environ Health 2006; 32: 51-60.

21) Hougaard KS, Hannerz H, Bonde JP, Feveile H, Burr $\mathrm{H}$. The risk of infertility among hairdressers. Five-year follow-up of female hairdressers in a Danish national registry. Hum Reprod 2006; 21: 3122-6.

22) Rylander L, Axmon A, Torén K, Albin M. Reproductive outcome among female hairdressers. Occup Environ Med 2002; 59: 517-22.
23) Zhu JL, Vestergaard M, Hjollund NH, Olsen J. Pregnancy outcomes among female hairdressers who participated in the Danish National Birth Cohort. Scand J Work Environ Health 2006; 32: 61-6.

24) Rylander L, Källén B. Reproductive outcomes among hairdressers. Scand J Work Environ Health 2005; 31: 212-7.

25) Ronda E, Moen BE, García AM, Sánchez-Paya J, Baste V. Pregnancy outcomes in female hairdressers. Int Arch Occup Environ Health 2010; 83: 945-51.

26) Gallicchio L, Miller S, Greene $T$, Zacur H, Flaws JA. Cosmetologists and reproductive outcomes. Obstet Gynecol 2009; 113: 1018-26.

27) Halliday-Bell JA, Gissler M, Jaakkola JJ. Work as a hairdresser and cosmetologist and adverse pregnancy outcomes. Occup Med 2009; 59: 180-4.

28) Herdt-Losavio ML, Lin S, Druschel CM, Hwang SA, Mauer MP, Carlson GA. The risk of having a low birth weight or preterm infant among cosmetologists in New York State. Matern Child Health J 2009; 13: 90-7.

29) Axmon A, Rylander L. Birth weight and fetal growth in infants born to female hairdressers and their sisters. Occup Environ Med 2009; 66: 198-204.

30) Li X, Sundquist J, Sundquist K. Parental occupation and risk of small-for-gestational-age births: a nationwide epidemiological study in Sweden. Hum Reprod 2010; 25: 1044-50.

31) Meyer JD, Nichols GH, Warren N, Reisine S. Maternal occupation and risk for low birth weight delivery: assessment using state birth registry data. J Occup Environ Med 2008; 50: 306-15.

32) Goulet L, Thériault G. Stillbirth and chemical exposure of pregnant workers. Scand J Work Environ Health 1991; 17: 25-31.

33) John EM, Savitz DA, Shy CM. Spontaneous abortions among cosmetologists. Epidemiology 1994; 5: 147-55.

34) Vaughan TL, Daling JR, Starzyk PM. Fetal death and maternal occupation. An analysis of birth records in the State of Washington. J Occup Med 1984; 26: 676-8.

35) Niedhammer I, O'Mahony D, Daly S, Morrison JJ, Kelleher CC; Lifeways Cross-Generation Cohort Study Steering Group. Occupational predictors of pregnancy outcomes in Irish working women in the Lifeways cohort. BJOG 2009; 116: 943-52.

36) Labrèche F, Forest J, Trottier M, Lalonde M, Simard R. Characterization of chemical cxposures in hairdressing salons. Appl Occup Environ Hyg 2003; 18: 1014-21.

37) Tsigonia A, Lagoudi A, Chandrinou S, Linos A, Evlogias N, Alexopoulos EC. Indoor air in beauty salons and occupational health exposure of cosmetologists to chemical substances. Int $\mathrm{J}$ Environ Res Public Health 2010; 7: 314-24.

38) Ronda E, Hollund BE, Moen BE. Airborne exposure to chemical substances in hairdresser salons. Environ Monit Assess 2009; 153: 83-93.

39) Witorsch RJ, Thomas JA. Personal care products 
and endocrine disruption: a critical review of the literature. Crit Rev Toxicol 2010; 40: 1-30.

40) Gomez E, Fenet H, Pillon A, Rosain D, Balaguer P, Casellas C. Substances included in the formulation of personal care products and endocrine disruptors. Environ Risques Santé 2006; 5: 275-79 (French) .

41) Kortenkamp A. Low dose mixture effects of endocrine disrupters: implications for risk assessment and epidemiology. Int J Androl 2008; 31: 233-40.

42) Dodson RE, Nishioka M, Standley LJ, Perovich LJ, Brody JG, Rudel RA. Endocrine disruptors and asthma-associated chemicals in consumer products. Environ Health Perspect 2012; 120: 935-43.

43) Koniecki D, Wang R, Moody RP, Zhu J. Phthalates in cosmetic and personal care products: concentrations and possible dermal exposure. Environ Res 2011; 111: 329-36.

44) Hollund BE, Moen BE. Chemical exposure in hairdresser salons: effect of local exhaust ventilation. Ann Occup Hyg 1998; 42: 277-82.
45) Paul J. Healthy beginnings : guidance on safe maternity at work. Geneva: International Labour Organization, 2004.

46) Peretz J, Gallicchio L, Miller S, Greene T, Zacur H, Flaws JA. Infertility among cosmetologists. Reprod Toxicol 2009; 28: 359-64.

47) Jaddoe VW, Bakker R, Hofman A, Mackenbach JP, Moll HA, Steegers EA. Moderate alcohol consumption during pregnancy and the risk of low birth weight and preterm birth. The generation $\mathrm{R}$ study. Ann Epidemiol 2007; 17: 834-40.

48) Fierens T, Servaes K, Van Holderbeke M, Geerts L, De Henauw S, Sioen I. Analysis of phthalates in food products and packaging materials sold on the Belgian market. Food Chem Toxicol 2012; 50: 2575-83.

49) Matsumoto M, Hirata-Koizumi M, Ema M. Potential adverse effects of phthalic acid esters on human health: a review of recent studies on reproduction. Regul Toxicol Pharmacol 2008; 50: 37-49. 